\title{
Laboreal
}

Volume $14 \mathrm{~N}^{\circ} 1$ | 2018

$\mathrm{O}$ regresso ao emprego após um acidente de trabalho

\section{What is watt?: história de uma medida}

What is watt?: historia de una medida

What is watt?: histoire d'une mesure

What is watt?: history of a measure

\section{François Vatin}

Traductor. Liliana Cunha

\section{OpenEdition}

\section{Journals}

Edición electrónica

URL: http://journals.openedition.org/laboreal/568

DOI: $10.4000 /$ laboreal.568

ISSN: 1646-5237

Editor

Universidade do Porto

Referencia electrónica

François Vatin, « What is watt?: história de uma medida », Laboreal [En línea], Volume $14 \mathrm{~N}^{0} 1 \mid 2018$

Publicado el 01 julio 2018, consultado el 14 septiembre 2020. URL : http://journals.openedition.org/ laboreal/568

Este documento fue generado automáticamente el 14 septiembre 2020.

\section{c) (i) (8)}

Laboreal está licenciado com uma Licença Creative Commons - Atribuição-NãoComercial 4.0 Internacional. 


\title{
What is watt?: história de uma medida
}

\author{
What is watt?: historia de una medida \\ What is watt?: histoire d'une mesure \\ What is watt?: history of a measure
}

François Vatin

Tradución : Liliana Cunha

\section{NOTA DEL EDITOR}

http://dx.doi.org/10.15667/laborealxiv0118fv

\section{De Watt aos watts}

1 Com uma maiúscula, trata-se de James Watt (1736-1819), engenheiro britânico, cujo nome está associado ao desenvolvimento da máquina a vapor. Na década de 1760 , ele aprimora a máquina de Newcomen e, em 1774, cria um negócio perto de Birmingham para produzir essas máquinas, que logo se tornaram uma referência em toda a Europa. Com letra minúscula, o watt é uma unidade de energia que aparece na década de 1880 na França, como na Grã-Bretanha, no contexto do desenvolvimento de motores elétricos. Enquanto o termo watt se refere obviamente a James Watt, a conexão entre os dois não é óbvia, uma vez que a medida em watt é tardia e aparece no contexto tecnológico da 'segunda' revolução industrial, enquanto James Watt permaneceu como um símbolo da primeira revolução.

2 Para compreender a génese da denominação de watt, é preciso passar por uma expressão que aparece na década de 1850: o 'cavalo de Watt'. James Watt mediu, de facto, a capacidade das suas máquinas em 'força de cavalo' ('power of the horse'), que está na origem do 'cavalo-vapor' ( horsepower). A lógica de uma tal medida é comercial. 
Trata-se de avaliar a máquina pelo número de cavalos que ela pode substituir. Os engenheiros do século XIX não foram os primeiros a raciocinar dessa maneira. Já em 1699, Guillaume Amontons tinha procurado, a fim de convencer os seus colegas académicos, avaliar a potência da 'máquina de fogo' que submetia ao seu julgamento, calculando o número de homens ou de cavalos que ela poderia substituir. Isso conduzilo-á a liderar o primeiro estudo ergonómico do trabalho industrial, o dos polidores de espelho da jovem empresa de Saint-Gobain. Ele mediria a sua atividade como o produto de uma força (exercida sobre o polidor) pela velocidade do movimento deste último, que corresponde a uma potência [1].

3 Convencionalmente, em França, o valor do cavalo-vapor foi estabelecido no início da década de 1830 em 75 Kilogramas por segundo, o que significaria que um cavalo teria a capacidade muscular para elevar um peso de 75 kilogramas a um metro por segundo. Esta medida não foi convencionada sem causar uma certa hesitação que denunciou o Capitão (e futuro Almirante) Simeon Bourgeois, em 1854, num relatório ao ministro da Marinha, Theodore Ducos: 'Na realidade, o cavalo-vapor não tem atualmente um valor determinado, e é estabelecido entre as expressões de cavalo nominal, cavalo de Watt, cavalo efetivo, etc. uma confusão deplorável ... ' [2].

O watt corresponde, no sistema internacional de medidas físicas contemporâneas (sistema MKSA por metro, kilograma, segundo, ampere), a um joule por segundo. 0 joule, unidade standard moderna de energia, é ele próprio igual a 0,102 kilogramas. Um 'cavalo de Watt' (uma potência de 75 Kilogramas por segundo) representa, portanto, cerca de 736 watts. Ao passar de cavalo de Watt para watt, passamos de uma medida convencional da potência cavalar, inventada no século XIX, mas cujo espírito releva de medidas antigas estudadas por Wittold Kula [3], ao rigor desencarnado do sistema métrico estendido da física contemporânea.

\section{Do trabalho à potência}

5 Além dessas questões metrológicas, a emergência do watt como medida de referência no campo da indústria elétrica, no final do século XIX, é testemunha de uma inversão entre os conceitos de trabalho e de potência.

6 No início do século XIX, definiu-se o 'trabalho de uma força' como um peso elevado a uma determinada altura. A ação de qualquer máquina pode, de facto, ser reduzida à ação de elevação de um peso, sob a condição de serem pensadas as engrenagens necessárias. Ora, essa ação fornecia a grandeza de base da física desde Galileu e Newton, pois consistia na grandeza que era requerida para se opor à força da gravidade. Qualquer 'trabalho' realizado por uma máquina poderia, portanto, ser medido como o produto de uma força pelo deslocamento de seu ponto de aplicação, como o era na elevação vertical de um peso. Chamou-se a essa grandeza o 'trabalho', porque era considerada equivalente ao 'trabalho' realizado pelos homens ou pelas bestas de carga [4]. No final do século XVIII, Charles Augustin Coulomb procurou medir a 'quantidade de ação que os homens podem produzir de acordo com o modo como usam as suas forças'. Ele tomou como exemplo de base a elevação de uma carga numa escada. $\mathrm{Na}$ mesma época, Edme Reignier inventou o 'dinamómetro', instrumento que permitia medir a força instantânea numa configuração de tensão. Podia-se, portanto, facilmente calcular o trabalho realizado pelos animais de tração instalando um dinamómetro no animal e carregando-o. 
7 O conceito de potência foi libertado do de trabalho. Ele corresponde à quantidade de trabalho realizado num dado tempo. Em 1826, o engenheiro Charles Dupin propôs chamar esta medida de 'dínamo', expressão que não perpetuou. Como os homens e os animais, as máquinas desenvolvem trabalho. Mas uma rutura se opera na conceção mesmo da máquina no início do século XIX. Até lá, o termo designava um instrumento de transformação do movimento mecânico, tal como um moinho, colocado em movimento pelo vento ou pela água para gerar um movimento preciso e controlado (por exemplo, a moagem do grão). Assim, distingue-se as máquinas dos 'motores', que estão na origem deste movimento, e entre estes dois tipos: os motores 'inanimados' (o vento, a água) e 'animados' (os homens e os animais). A origem da força animal permanece misteriosa, mesmo se, de uma forma muito sábia, Lavoisier a concebeu, desde 1789, como uma forma de combustão.

8 A difusão da 'máquina a vapor', em grande parte iniciada por James Watt e seu colega Matthew Boulton, vira do avesso essas representações. Trata-se, de facto, de uma máquina 'motriz', que produz movimento a partir da combustão do carvão. Esta inovação tecnológica está na origem de uma revolução científica na década de 1840: a invenção da termodinâmica. Vamos perceber, com efeito, que podemos considerar que o calor e o trabalho são duas formas da mesma grandeza física: a energia. Vai-se procurar medir, em conformidade com as intuições de Antoine Lavoisier, o 'equivalente mecânico do calor'. Portanto, as formas de energia reconhecidas pelos físicos não deixarão de se expandir: a energia eletromagnética, a energia contida nas ligações químicas (cuja evidência por Marcellin Berthelot na década de 1880 permitirá a elaboração, no final do século, da bioenergética, que alimentará o movimento das ciências do trabalho $\left.{ }^{[}\right]$), mais tarde a energia atómica ...

Ao passar do trabalho mecânico para a energia, passamos de uma força em ato (o movimento mecânico) para uma força em potência. Já em 1834, Adhémar Barré de Saint-Venant escreveu que o conceito de 'trabalho mecânico' tinha que ser complementado pelo de 'capital mecânico' [ $\left.{ }^{6}\right]$. Não se abandona a metáfora económica na origem do conceito de trabalho, definido pelo engenheiro Claude-Louis Navier, em 1829, como um 'dinheiro mecânico'. Mas é amplificado. Passa-se, num movimento que não poderia deixar de evocar o pensamento de Karl Marx, de uma teoria da troca para uma teoria do capital. Não é de admirar que o conceito de 'potência' tenha precedência sobre o de trabalho. No ensino elementar da física, há muito tempo que foi deduzida a 'potência' do 'trabalho'. Hoje deduz-se o 'trabalho' da 'potência'. A linguagem comum reteve o kilowatt, de que é deduzido, para medir o seu consumo de energia, o kilowatthora (potência multiplicada por um tempo). Esta é uma energia cujas dimensões físicas são as mesmas que as do trabalho. O kilowatt-hora pode, portanto, ser medido em kilogramas (o kilowatt-hora é de 3600 kilojoules, ou seja, 367200 kilogramas).

10 A evolução das denominações físicas é testemunha daquelas, combinadas da ciência e do mundo social que a incorporam. Da força bruta de homens e dos animais evocada pela noção do kilograma, passou-se ao poder etéreo de uma misteriosa corrente elétrica. O laborioso cavalo de Watt foi substituído por um ser mítico, o kilowatt-hora, que aos mais antigos, em França, pode lembrar os terríveis gritos que ele proferiu quando consumidores inconsequentes e sem piedade 'os jogaram pelas janelas' [7]. 


\section{BIBLIOGRAFÍA}

Bourgeois, S. (1854). Rapport à son excellence M. Ducos sur la navigation commerciale. Paris.

Kula, W. (1970). Des mesures et des hommes. Paris: Maison des sciences de l'homme (édition originale polonaise, 1970).

Saint-Venant, B. (1834). Mémoire sur les théorèmes de la mécanique générale (présenté le 14 avril 1834). Académie des sciences, Archives de l'Ecole Polytechnique, Fonds Saint-Venant, carton $\mathrm{n}^{\circ} 19$.

Vatin, F. (1993). Le travail. Economie et physique (1780-1830). Paris: PUF. Tradução parcial em português: ABCM (Associação Brasileira de Engenharia e Ciências Mecânicas) (2017). O Trabalho. Economia e Física, vol. 20, n 2, p. 25-39. Tradução completa no prelo: Vatin, F. (2018). As medidas do trabalho: física e economia. Campinas: Mercado de Letras.

Vatin, F. (1999). Le travail, sciences et société. Bruxelles: Éditions de l'Université de Bruxelles. Tradução portuguesa: Vatin, F. (2002). Epistemologia e Sociologia do Trabalho. Lisboa: Instituto Piaget. Tradução espanhola: Vatin, F. (2004). Trabajo, Ciencias y sociedad. Ensayos de sociologia y epistemologia del trabajo. Buenos-Aires et Mexico: Lumen Humanitas.

\section{NOTAS}

1. O poder mecânico é um trabalho dividido por um tempo. $O$ trabalho é o produto de uma força por uma distância. Se assumirmos a velocidade constante, a potência pode ser definida como o produto de uma força por uma velocidade, que é uma distância dividida por um tempo.

2. Bourgeois, S. (1854). Rapport à son excellence M. Ducos sur la navigation commerciale. Paris.

3. Kula, W. (1970). Des mesures et des hommes. Paris: Maison des sciences de l'homme (édition originale polonaise, 1970).

4. Vêr em Vatin, F. (1993). Le travail. Economie et physique (1780-1830). Paris: PUF. Tradução parcial em português: ABCM (Associação Brasileira de Engenharia e Ciências Mecânicas) (2017). 0 Trabalho. Economia e Física, vol. 20, $n^{\circ}$ 2, p. 25-39. Tradução completa no prelo: Vatin, F. (2018). As medidas do trabalho: física e economia. Campinas: Mercado de Letras.

5. Vêr em Vatin, F. (1999). Le travail, sciences et société. Bruxelles: Éditions de l'Université de Bruxelles. Tradução portuguesa: Vatin, F. (2002). Epistemologia e Sociologia do Trabalho. Lisboa: Instituto Piaget. Tradução espanhola: Vatin, F. (2004). Trabajo, Ciencias y sociedad. Ensayos de sociologia y epistemologia del trabajo. Buenos-Aires et Mexico: Lumen Humanitas.

6. Saint-Venant, B. (1834). Mémoire sur les théorèmes de la mécanique générale (présenté le 14 avril 1834). Académie des sciences, Archives de l'Ecole Polytechnique, Fonds Saint-Venant, carton $\mathrm{n}^{\circ}$ 19.

7. 'Não jogue os seus Kilowatt-hora pelas janelas' era um slogan da propaganda governamental francesa para incitar o público a moderar os seus consumos no contexto da crise petrolífera no final dos anos de 1970. 
ÍNDICE

Temas: o Dicionário

\section{AUTORES}

FRANÇOIS VATIN

Université de Paris-Nanterre Laboratoire 'Institutions et dynamiques historiques de l'économie et de la société' (IDHES-CNRS) Maison ‘Max Weber' Université de Paris-Nanterre 200 avenue de la République 92000 Nanterre vatin@parisnanterre.fr 